This is the final pre-publication version of:

Pilotto, F., Bertoncin, A., Harvey, G.L., Wharton, G. and Pusch, M.T. (2014) Diversification of stream invertebrate communities by large Wood. Freshwater Biology 59: 2571-2583.

\title{
Diversification of stream invertebrate communities by large wood
}

Francesca Pilotto ${ }^{1,2,3}$, Andrea Bertoncin ${ }^{1}$, Gemma L. Harvey ${ }^{3}$, Geraldene Wharton ${ }^{3}$, Martin T. Pusch $^{1}$

${ }^{1}$ Leibniz Institute of Freshwater Ecology and Inland Fisheries (IGB), Berlin, Germany

${ }^{2}$ Institute of Biology, Freie Universität Berlin, Berlin, Germany

${ }^{3}$ School of Geography, Queen Mary University of London, London, U.K.

Corresponding author: Francesca Pilotto, Leibniz Institute of Freshwater Ecology and Inland Fisheries (IGB), Müggelseedamm 301, 12587 Berlin, Germany. E-mail: pilotto@igb-berlin.de

Abbreviated title: Diversification of invertebrate communities

Key words: sediment - mesohabitat - hydromorphology - diversity - lowland river 


\section{Summary}

1. To evaluate the effects of large wood (LW) on benthic habitats and macroinvertebrates in sand-bed lowland rivers, we compared invertebrate communities recorded on four pieces of LW (12 samples in total) and around them (60 samples) with those in four control sites in the same river (four samples).

2. Mean flow velocity was $32 \%$ lower in the channel areas surrounding the LW than in control sites, while median sediment grain size was $50 \%$ higher, and the organic matter content of the riverbed sediments was $287 \%$ higher. At the same time, habitat conditions showed 3 - 1000 fold increases in variance for five key abiotic habitat descriptors in the surrounding channel extending at least $60 \mathrm{~cm}$ upstream and $160 \mathrm{~cm}$ downstream of the LW.

3. Three habitat patches typically occurred around the LW pieces: scouring pools, sand bars and accumulations of organic matter. These patches were colonized by distinctive invertebrate communities (e.g. accumulations of organic matter and gravel hosted 15 and 2 indicator taxa, respectively), that overall harboured $110 \%$ more taxa and exhibited a $168 \%$ higher diversity than control sites. The LW itself contributed only a small fraction to these increases, exhibiting a $15 \%$ increase in taxa richness and a $21 \%$ increase in species diversity compared to the control sites.

4. The diversification of benthic invertebrate communities colonizing streambed sediments around LW could be directly linked to the much more heterogeneous habitat conditions recorded there. Thus, local additions of large wood within river restoration programmes have the potential to promote the establishment of diverse invertebrate communities in extended areas of a river channel. 


\section{Introduction}

Large wood (LW) in river channels represents a significant hydraulic roughness element which alters river flows and causes changes to channel depth, width and velocity profiles at small and medium scales (Mutz, 2000; Montgomery et al., 2003; Gurnell \& Linstead, 1998; Wohl, 2013; Keller \& Swanson, 1979). The presence of LW results in more complex flow patterns and a generally lower average flow velocity (Ehrman \& Lamberti, 1992; Gippel et al., 1996). In retarding flows, LW also enhances the retention of fine inorganic sediments and organic matter (Ehrman \& Lamberti, 1992; Daniels, 2006; Smock, Metzler \& Gladden, 1989; Cordova et al., 2008), which leads to a more heterogeneous distribution and sorting of the sediments (Montgomery et al., 2003). These modifications of hydromorphology by LW are well documented for rivers with high-gradient and/or coarse sediments and large accumulations of LW (Gurnell et al., 2002; Buffington \& Montgomery, 1999; Keller \& Swanson, 1979), but there have been few studies of the influence of isolated pieces of LW in sand-dominated low-gradient rivers (Daniels, 2006). However, the modifications of hydromorphology by LW are potentially important in such rivers characterized by lower energy conditions and more homogeneous flows. LW may be the only stable substratum in the river and therefore a significant trigger creating more diverse flow and habitat conditions which is only paralleled by the seasonal appearance of submerged macrophyte stands (Kail, 2003; Mutz, 2000; Webb \& Erskine, 2005; Daniels, 2006). Given this crucial role for hydromorphology, LW has been introduced into rivers for restoration purposes in North America (Roni et al., 2002), Europe (Kail et al., 2007), Australia (Lester \& Boulton, 2008) and Japan (Nakano et al., 2008), where it triggers significant morphological changes of stream reaches (e.g. Kail et al., 2007).

The impact of LW on lotic macroinvertebrate communities has also been extensively studied during the last two decades. It has been shown that LW provides trophic resources, flow refugia, shelter against predation and attachment options (O'Connor, 1991; Everett \& Ruiz, 1993; Drury 
\& Kelso, 2000; Hoffmann \& Hering, 2000; Benke \& Wallace, 2003). However, most of those studies have been conducted in high-gradient streams in North America, while only few studies have dealt with European rivers, or lowland channels (Hoffmann \& Hering, 2000; Gerhard \& Reich, 2000). Furthermore, most studies have focused on the wood-dwelling benthic invertebrate assemblages (Hoffmann \& Hering, 2000; Benke \& Wallace, 2003) whereas few (Wallace, Webster \& Meyer, 1995; Gerhard \& Reich, 2000; Hilderbrand et al., 1997) have investigated the potential effects of LW on benthic communities colonizing the streambed sediments around a piece of LW.

In mountain streams the addition of LW typically results in sediment deposition upstream of the logs and the formation of more mesohabitats. This leads to higher overall benthic invertebrate densities and taxa richness (Gerhard \& Reich, 2000), with a decrease in the abundance and biomass of scrapers and filterers, and an increase in that of collectors and predators (Wallace, Webster \& Meyer, 1995). In low-gradient rivers, LW is associated with an increase in the number of pools (Hilderbrand et al., 1997). Moreover, LW-induced mesohabitats respond in different ways to flood disturbance, which leads to a greater resistance of fauna to floods (Palmer et al., 1996). However, previous studies have considered only the effects on the area upstream of LW (Wallace, Webster \& Meyer, 1995) and have not analyzed the effects of a single LW structure on surrounding channel areas or the distance to the next LW. Thus, there is an obvious knowledge gap on the effects of LW on hydromorphology and on the benthic fauna in surrounding channel areas.

Our study aimed to quantify for the first time the effects of LW on the structural and functional composition of benthic invertebrate assemblages in the riverbed sediments at the mesohabitat scale (centimetres to meters, as defined by Armitage, Pardo \& Brown (1995), Pardo \& Armitage (1997) and Harper \& Everard (1998)) and to relate those effects to the hydromorphological changes induced by single LW pieces. For that purpose, we chose a European sand-bed 
lowland river that is rich in naturally-occurring LW. Through this study we aimed to clarify the hydromorphological processes triggered by the presence of LW that lead to increasing mesohabitat heterogeneity and biotic diversity. We hypothesized that: i) the presence of LW would be associated with distinct patches of flow conditions and substratum type; ii) these patches would host distinct invertebrate assemblages due to species-specific preferences to particular abiotic conditions (Schröder et al., 2013); and iii) the patchy distribution of substratum types would favour small scale dispersal among neighbouring patches, which would lead to higher biotic diversity (Beisel, Usseglio-Polatera \& Moreteau, 2000).

\section{Methods}

Large wood (LW) is conventionally defined as material larger than $0.1 \mathrm{~m}$ in diameter and $1 \mathrm{~m}$ in length (Gippel et al., 1996), in the form of branches or whole trees that fall into the channel due to, for example, bank erosion, wind or beaver activity, or are intentionally added as a measure for river restoration.

\section{Study area}

The study was carried out in the Pliszka River, a tributary to the Oder River (Czech/Polish: Odra) in western Poland (Fig. 1). The Pliszka is a low gradient, sand-dominated lowland river with mostly forested riparian zones and a length of $56 \mathrm{~km}$. Environmental and biotic data were recorded along a $100-\mathrm{m}$-long study reach $\left(52^{\circ} 14^{\prime} 58^{\prime \prime} \mathrm{N}, 14^{\circ} 44^{\prime} 18^{\prime \prime} \mathrm{E}\right)$, which was characterized by forested banks (mainly alder [Alnus glutinosa]) and abundant in-channel LW (mostly alder tree trunks). We counted 19 LW pieces ranging in length between 1.29 and $13.60 \mathrm{~m}$ (mean $7 \mathrm{~m}$ ) and in diameter between 12 and $40 \mathrm{~cm}$ (mean $25 \mathrm{~cm}$ ) per $100 \mathrm{~m}$ of channel. Flow during the study was at near-bankfull stage; mean channel width was $9.55 \mathrm{~m}$, mean water depth $0.58 \mathrm{~m}$ and discharge $1.82 \mathrm{~m}^{3} \mathrm{~s}^{-1}$. Due to the limited power of this lowland river, nearly all alder logs falling 
into the channel remain in place as single logs, mostly aligned across the channel perpendicular to the flow direction.

\section{Study design}

Field work was carried out in October and November 2012. Four representative pieces of LW (in terms of size and location within the river channel) were selected within the study reach as replicates, ranging in diameter between 22 and $40 \mathrm{~cm}$ and in length between 6.20 and $13.60 \mathrm{~m}$. These were single logs with approximately perpendicular orientation to river flow, and partially anchored in the bed sediment. All were at least $5 \mathrm{~m}$ from each other, and situated in a relatively straight reach, which avoided confounding their effects with those of nearby LW pieces. As water depths along the LW ranged between $32.5 \mathrm{~cm} 140.0 \mathrm{~cm}$, the logs blocked $18-71 \%$ of total water depth (Table 1) and $17-51 \%$ of the river channel cross-section.

Sediment composition around the LW pieces was visually surveyed within an area of $2 \mathrm{~m}$ downstream and $2 \mathrm{~m}$ upstream of each LW log, and scored as: coarse sand and gravel ('gravel'); sand bars and shifting sand ('sand'); and accumulations of both fine and coarse particulate organic matter, as small pieces of wood and leaves ('organic matter'). The three substratum types were visible in proximity to all four replicate LW pieces.

In each of the three substratum types we established a transect across the LW, with sampling sites located 160, 60 and $10 \mathrm{~cm}$ downstream and at 10 and $60 \mathrm{~cm}$ upstream of the LW. Those distances were chosen based on the preliminary visual assessment of riverbed sediment compositions as potentially representative of a gradient of influence of LW. This sampling grid was followed for all four replicate logs, and was supplemented by four samples ('control') that were collected randomly from riverbed sediments (mainly sand) in the upstream part of the reach and were not influenced by the presence of LW (distance to the next LW $>10 \mathrm{~m}$, distance to the next control sample $>3 \mathrm{~m}$ ). At each sampling site, data on invertebrate colonization, flow 
velocity and sediment properties were collected. Additional invertebrate samples and flow measurements were taken from the surface of the LW piece directly within each transect (3 samples per LW).

\section{Sampling for macroinvertebrates}

Benthic macroinvertebrates were sampled using a Surber sampler (frame size $23 \times 23 \mathrm{~cm}$, mesh size $500 \mu \mathrm{m})$. The material from five replicate Surber samplings was pooled to produce one sample, which thus covered a total area of $0.26 \mathrm{~m}^{2}$. Invertebrates sampled from the LW surface were dislodged by brushing, and the material was then collected with the net. Samples were preserved in $70 \%$ ethanol and processed in the laboratory. Animals were counted and identified to the lowest taxonomic level possible under a binocular microscope with 10x magnification. Samples were mostly identified to species or genus level, while Gammaridae (with the exception of Gammarus roeselii) and some Trichoptera were identified to family, Chironomidae to subfamily, and Oligochaeta as order (the complete taxa list is reported in Table S1 in Supporting Information).

Based on the invertebrate taxonomic abundances, the following ecological metrics were computed using the software ASTERICS (AQEM Consortium, 2008): diversity metrics (Shannon-Wiener diversity index, Evenness); absolute and relative abundances of feeding groups (grazers and scrapers, shredders, gatherer-collectors, xylophagous, miners, active filterers, passive filterers, predators and parasites). Since samples with more individuals tend to be richer in species, we computed the standardized taxonomic richness ('taxa richness') using an individual-based rarefaction approach (Gotelli \& Colwell, 2001; Hurlbert, 1971) with the function 'rarefy' in the R (R Core Team, 2013) package 'Vegan' (Oksanen et al., 2013).

\section{Environmental variables}


At each sampling site, near-bed $(5 \mathrm{~cm}$ above the sediment) 3D flow measurements were recorded for 1 minute (Buffin-Bélanger \& Roy, 2005) at $1 \mathrm{~Hz}$, using a 'FlowTracker' (SonTek) Acoustic Doppler Velocimeter in order to assess the hydraulic conditions experienced by benthic invertebrates (Jowett, 2003). From those measurements, mean flow velocity was computed based on the three recorded components of the flow velocity (streamwise, $\mathrm{Vx}$, transverse, $\mathrm{Vy}$, and vertical velocity, $\mathrm{Vz}$ ) as $\mathrm{Mean} \mathrm{V}=\sqrt{V x^{2}+V y^{2}+V z^{2}}$, with $\mathrm{Vx}, \mathrm{Vy}$ and $\mathrm{Vz}$ being the mean velocity values over 1 minute. The standard deviation of $V x$ was used as a proxy for hydraulic turbulence (Enders, Boisclair \& Roy, 2003).

At the same sites, a sediment core (diameter $10 \mathrm{~cm}$, depth $5 \mathrm{~cm}$ ) was collected. Sediment samples were dried in the laboratory at $60^{\circ} \mathrm{C}$ for $36 \mathrm{~h}$ and then sieved through a 12-level sieving cascade with a sieve shaker. Each fraction was then re-dried at $60^{\circ}$ and weighed. Organic content was determined by subsequent burning of samples at $550^{\circ}$ for $5 \mathrm{~h}$. From the dry weight of the 12 fractions, distribution curves were calculated and the median grain size (D50) and the $16^{\text {th }}$ and $84^{\text {th }}$ percentiles (D16 and D84) were computed. Sediment sorting index was then

obtained as $\frac{D 84-D / 6}{2}$ (Liébault \& Piégay, 2001). The sorting index value is close to 0 for homogeneous samples and increases with increasing heterogeneity of the grain sizes.

\section{Data analysis}

Records from benthic sampling sites were analysed by running a PCA on standardized environmental variables, as mean flow velocity, turbulence, median grain size, sorting index, percentage of organic matter in the sediments and water depth. Differences in the values of the invertebrate metrics and environmental variables were tested for effects of 1) substratum type and 2) distance from the LW by performing linear mixed effects (LME) analyses. Thus, two LME models were analysed: 
[1] Metric $\sim$ Substratum+(1|LWid)+(1+Substratum|Distance $)$

[2] Metric Distance+(1|LWid)+(1+Distance|Substratum)

where LWid identifies the single LW log (i.e. LW1, LW2, LW3 and LW4). Those models considered substratum (in [1]) or distance (in [2]) as fixed factor, random intercepts for LWid, random slopes and intercepts for the second factor (distance in [1], and substratum in [2]). The models were tested by likelihood ratio tests against the reduced model (without the fixed effect). When necessary, environmental variables and tested metrics were $\log (x+1)$-transformed before in order to meet the normality criterion (Table 2). Residuals were tested for normality by applying the Wilk-Shapiro test. Samples from the LW surface and control samples were excluded from LME analysis because of the interaction between substratum and distance (i.e. LW samples were the only ones at distance $=0 \mathrm{~cm}$, control samples at distance $>10 \mathrm{~m}$ ), which prevented disentanglement of the effects of those two factors.

Since LME showed that distance did not exert a significant effect on invertebrate metrics, we used the non-parametric Kruskal-Wallis test to compare the values of the metrics among the substratum types in the areas surrounding the LW (gravel, sand and organic matter), the LW itself and the control samples. The variances of the abiotic variables recorded in the areas surrounding the LW and in the control area were compared using the rank-based Levene's test based on the absolute deviations from the mean.

The overall value of the diversity metrics in the LW area were computed as mean values for each substratum type, weighted by their proportional coverage within the area of $2 \mathrm{~m}$ downstream and $2 \mathrm{~m}$ upstream of the LW.

Non metric multidimensional scaling (nMDS) and analysis of similarities (ANOSIM) were applied to the $\log (x+1)$-transformed invertebrate taxonomic abundances in order to plot the taxonomic composition of the communities inhabiting the various substratum types (control, LW, gravel, 
sand and organic matter), and to test for differences. For both analyses, distances among the samples were computed as Bray-Curtis dissimilarities. Based on this, the indicator value index, IndVal (Dufrêne \& Legendre, 1997; Cáceres \& Legendre, 2009) was computed in order to identify indicator taxa for each substratum type (control, LW, gravel, sand and organic matter). There, a taxon is considered to be an indicator of a certain group of sites if it has a large mean abundance within that group compared to the other groups, and if it is present in most sites of that group (Borcard, Gillet \& Legendre, 2011). For each taxon, the significance of the indicator value was obtained by a permutation test (Dufrêne \& Legendre, 1997).

Constrained ordinations of taxonomic data were obtained with a redundancy analysis (RDA) in order to gather insights into the relative importance of each environmental variable in shaping the biotic community. RDA ordination is based on the computation of orthogonal axes that are linear combinations of the explanatory (environmental) variables, and which best explain the variation of the response (invertebrate) matrix (Borcard, Gillet \& Legendre, 2011). The analysis was conditioned on LWid in order to remove the variation caused by individual LW. Prior to the analysis, invertebrate abundances were Hellinger-transformed. The Hellinger transformation, when associated with Euclidean based ordination methods such as redundancy analysis (RDA), preserves the Hellinger distance among sites, which underweights the most abundant taxa (Legendre \& Gallagher, 2001). Samples from the LW surface and control samples were excluded from the RDA ordination because we were interested in the abiotic factors producing biotic diversity around the LW and because of the interaction between substratum and distance.

The statistical analyses were performed in R (R Core Team, 2013); we used the package “Vegan" (Oksanen et al., 2013) for PCA, nMDS, ANOSIM and RDA, the package "Indicspecies" (Cáceres \& Legendre, 2009) for the IndVal analysis, the package "Ime 4" (Bates, Maechler \& Bolker, 2012) for LME, the package "lawstat" (Noguchi et al., 2009) for the Levene's test and the 
package "Agricolae" (Mendiburu, 2012) for the Kruskal-Wallis test and pairwise comparisons with Bonferroni correction.

\section{Results}

\section{Hydromorphology}

LW covered $10 \pm 2 \%$, gravel $14 \pm 4 \%$, sand $40 \pm 9 \%$ and organic matter $35 \pm 5 \%$ of the area extending from $2 \mathrm{~m}$ upstream to $2 \mathrm{~m}$ downstream from LW. Gravel habitat occurred where the LW blocked a smaller percentage of the water column in comparison to sand and organic matter habitats (Table 1).

The PCA revealed that the main gradient of environmental conditions (53\% of the variance) was defined by flow velocity, sorting index, water depth, turbulence and sediment grain size (Fig. 2). The second gradient (18\% of the variance) was mainly driven by the content of sediment organic matter. Thus, the organic matter content of sediments was mostly independent from the other abiotic variables. The control samples took an intermediate position in this ordination plot, while the organic matter and gravel sites were spread over a much larger range of environmental conditions.

Linear mixed effects (LME) analysis confirmed that flow velocity, sediment sorting index and water depth differed significantly $(p<0.01)$ among substratum types, with highest values recorded on gravel (Table 2). The distance of the sampling site from the LW was not significant for any variables $(p>0.05)$, indicating that the $160 \mathrm{~cm}$ downstream and $60 \mathrm{~cm}$ upstream distances that were surveyed in this study did not represent a significant distance gradient and thus that the effect of the LW on those abiotic variables extended further until their values eventually converged to those recorded at the control site. 
The abiotic variables defining streambed hydromorphology spanned much larger ranges around the LW than at the control site (Table 3 and Fig. 3). The variance of water depth was 25 times higher (LW area $1161 \mathrm{~cm}^{2}$, control $43.7 \mathrm{~cm}^{2}$; Levene's test $6.66, \mathrm{p}<0.01$ ) in the substratum types around the LW than in the control sites; the variance of mean velocity was 170 times higher (LW area $0.0181 \mathrm{~m}^{2} \mathrm{~s}^{-2}$, control $0.0001 \mathrm{~m}^{2} \mathrm{~s}^{-2}$; Levene's test $\left.9.65, \mathrm{p}<0.01\right)$; the variances of grain size and sorting index were nearly 1000 times higher (LW area $2.063 \mathrm{~mm}^{2}$, control $0.002 \mathrm{~mm}^{2}$; Levene's test $10.53, \mathrm{p}<0.01$ ); the variance of sediment organic matter content was 29 times higher (LW area $17.2 \%$ squared, control $0.57 \%$ squared; Levene's test $6.80, p<0.01$ ); and the variance of flow turbulence was three times higher, but the difference was not statistically significant ( $\mathrm{LW}$ area $8.4 \times 10^{-4} \mathrm{~m}^{2} \mathrm{~s}^{-2}$, control $2.1 \times 10^{-4} \mathrm{~m}^{2} \mathrm{~s}^{-2}$; Levene's test 1.77 , $\mathrm{p}=0.18)$.

The presence of LW in the studied river resulted in a $32 \%$ decrease in mean flow velocity, a $19 \%$ increase in turbulence, a $28 \%$ increase in water depth, a $50 \%$ increase in median sediment grain size, a $330 \%$ increase in sediment sorting index, and a $287 \%$ increase in the organic matter content of the sediment (gravel, sand and organic matter), compared to the control sites.

\section{Macroinvertebrates}

Several invertebrate metrics differed among the three visually-identified substratum types, as shown by LME analysis (Table 2). Again, the distance from the LW was not significant for any metric $(p>0.05)$. The benthic samples taken from the riverbed sediments around the LW and on the LW surface were characterized by significantly higher values of the diversity metrics (Shannon-Wiener diversity index and evenness) than the control samples (Fig. 4). Furthermore, the overall value of the metrics in the LW areas was $81 \%, 110 \%, 108 \%$ and $168 \%$ higher than in the controls for abundance, taxa richness, evenness and Shannon-Wiener diversity 
index, respectively. The contribution of the actual LW habitat to those increases was respectively $23 \%, 15 \%, 12 \%$ and $21 \%$. Within the functional feeding groups, collectors constituted the dominant feeding group in the control samples (ca. $80 \%$ ), and were also abundant on all other substrata (ranging between 26 and $45 \%$ ). In contrast, grazers and xylophagous taxa showed clear preferences to colonize LW, and shredders preferred organic matter and sand substratum types (Fig. 5). Similar trends were also found for the absolute abundances of collectors (Kruskal-Wallis test $p=0.002$ ), grazers (Kruskal-Wallis test $p<0.001$ ), xylophagous (Kruskal-Wallis test $\mathrm{p}=0.002$ ) and shredders (Kruskal-Wallis test $\mathrm{p}<0.001$ ). Moreover, active filterers were more abundant on gravel, sand, organic matter and control benthic patches (Kruskal-Wallis test $p<0.001$ ), while passive filterers preferred LW and gravel (Kruskal-Wallis test $\mathrm{p}=0.005)$. Predators (Kruskal-Wallis test $\mathrm{p}<0.001$ ) and parasites (KruskalWallis test $p<0.001$ ) were more abundant on LW and organic matter patches.

Due to these preferences, the various substratum types around the LW pieces (LW, gravel, sand and organic matter) were colonized by distinct macroinvertebrate communities (Fig. 6; ANOSIM, $R=0.39, p=0.001$ ). Despite this diversification of community structure around the $L W$, the taxonomic composition of the control samples remained statistically different from all other groups of samples (ANOSIM, control vs. LW R=0.96, $p=0.002$; control vs. organic matter $R=0.74, p=0.001$; control vs. gravel $R=0.34, p=0.034$ ), with the exception of sand (ANOSIM, $R=0.25, p=0.056$ ). As a consequence of those differences, two taxa were identified as indicative of gravel substrata, 13 indicative of LW, and 15 indicative of organic matter substrata (Table 4).

\section{Influence of environmental variables on macroinvertebrates}

The RDA ordination (Fig. $7 ; F(6)=2.40, p=0.001$ ) showed that the environmental variables explained $22 \%$ of the variance of the taxonomic matrix. The first RDA axis ( $13 \%$ of the explained variance) was determined by the sediment sorting index, water depth, mean flow 
velocity, grain size and turbulence, while the second RDA axis ( $4 \%$ of the explained variance) was positively correlated to distance from the LW, and negatively correlated to the content of organic matter in the sediment. RDA analysis also revealed that several taxa were clearly associated with environmental variables (Fig. 7). For example, the abundances of gammarids (Gammarus roeselii and Gammaridae gen. sp.) and Lepidostoma basale were associated with increasing content of organic matter and decreasing distance from the LW; Oligochaeta and Aphelocheirus aestivalis were more abundant at the sites with the greatest water depths. Baetis sp. and Simuliidae were associated with increasing median sediment grain size and decreasing organic matter content. Sphaeriidae (Pisidium sp. and Sphaerium sp.) were more abundant further from the LW, and also in areas of shallow water and slower flows. Thus, the diversification of invertebrate communities around the LW can be clearly linked to the increased heterogeneity of habitat conditions caused by the presence of LW.

\section{Discussion}

\section{Effects of $L W$ on the hydromorphology of surrounding channel areas}

Our surveys of the four pieces of LW demonstrated that they were surrounded by hydromorphological areas distinct from the control sites. Flow patterns emerging around LW are highly heterogeneous and variable (Montgomery et al., 2003). Flow velocity is often reduced within the roughness projection area of the LW, but increased where flow is concentrated in the remaining part of the channel cross-section (Gurnell \& Linstead, 1998; Wallace, Webster \& Meyer, 1995; Mutz, 2000). In mountain streams these flow patterns result in a shift from erosional to depositional processes that enhance the deposition of fine sediments and organic matter (Wallace, Webster \& Meyer, 1995; Buffington \& Montgomery, 1999). For the lowland sand-dominated Pliszka River we have demonstrated that LW triggers similar depositional processes where it blocks more than $30 \%$ of the water column, as we recorded sediment 
patches with up to a $53 \%$ decrease in median sediment particle size and up to $11 \%$ decrease in water depth compared to the control sites. On the other hand, we recorded patches of much coarser sediment (with up to $243 \%$ increase in median sediment particle size) where LW occupied a smaller proportion of the water column (i.e. less than $30 \%$ ) and concentrated water flow beneath the wood, thus creating a scouring area. Similarly, Mutz (2000) found coarser sized particles in the erosional areas in close proximity to LW in a sand-bed stream in Germany. Moreover, we recorded a substantial increase in the organic matter content of sediments close to LW, which has been previously reported for both mountain and lowland rivers (Ehrman \& Lamberti, 1992; Daniels, 2006; Smock, Metzler \& Gladden, 1989; Wallace, Webster \& Meyer, 1995). Thus, in sand-dominated low-gradient rivers LW seems to induce both erosional and depositional processes, which promotes habitat diversification.

\section{Effects of $L W$ on surrounding benthic macroinvertebrate communities}

The macroinvertebrate assemblage settled on the sand substrata sampled near the LW was not statistically different from the similarly sandy control sites in terms of taxonomic composition. However, it showed $72 \%$ higher taxa richness and $161 \%$ higher Shannon-Wiener diversity index and feeding types showed a more equal distribution. Shredders like gammarids can only be found in significant abundances on substrata with an elevated content of detritus (Dobson \& Hildrew, 1992), and the sand substrata surrounding the LW had substantially higher organic matter contents compared to the controls.

The substratum with high organic matter content harboured a very distinct invertebrate community, characterised by 15 indicator taxa, including the mussels Pisidium sp. and Sphaerium sp. which prefer fine sediments in shallow waters with moderate flow velocity (Hamill, Qadri \& Mackie, 1979; Schröder et al., 2013). Odonata larvae (i.e. Gomphus sp., Calopteryx sp. and Ophiogomphus cecilia) feed on any available prey (Corbet, 1980; Pritchard, 
1965), and thus may have benefitted from the higher total invertebrate abundance in organic matter patches.

Gravel patches were characterized by the most distinct physical habitat conditions, but only two indicator taxa could be identified: Hydropsyche pellucidula and Limnius sp. larvae. Another Hydropsyche species, $H$. siltalai, was found to be characteristic for LW. Those two net-spinning passive filter feeders $(H$. pellucidula and $H$. siltalai) require a firm substratum for the attachment of their nets (Schröder et al., 2013), and prefer high flow velocity to maximize the rate of seston capture in their nets (Boon 1978). In this study the two Hydropsyche species exhibited clearly different flow preferences (Boon, 1978): H. siltalai was more abundant on LW which was associated with higher flow velocities than the gravel patches, which was the preferred habitat of $H$. pellucidula. Taxa that preferentially colonized both gravel and wood were Baetis sp. (i.e. an indicator taxon for LW, see below), Aphelocheirus aesitivalis and Oligochaeta, as both gravel and LW provided coarse substratum and high flow velocity.

\section{Contribution of $L W$ to macroinvertebrate diversity}

Previous research has shown that the taxonomic richness, abundance and biomass of aquatic invertebrates are all higher on large wood than on riverbed sediment habitats (Hoffmann \& Hering, 2000; Benke \& Wallace, 2003; Smock, Metzler \& Gladden, 1989). We also recorded significantly higher taxa richness and diversity metrics on LW than for riverbed sediments in the control samples, and the macroinvertebrate community colonizing the wood surface significantly differed from the other recorded assemblages (control, gravel, sand and organic matter). The taxa characteristic of LW surfaces included Macronychus quadrituberculatus larvae (Coleoptera, Elmidae), Lype sp. (Trichoptera, Psychomyiidae), and Hydropsyche siltalai (Trichoptera Hydropsychidae), which are closely associated with wood (Hoffmann \& Hering, 2000). While M. quadrituberculatus and Lype sp. are obligate xylophages, $H$. siltalai is a passive filter feeder that 
uses LW as an attachment substratum in fast flowing water (Hoffmann \& Hering, 2000). Other indicator taxa are grazers and scrapers, including the elmid beetle larvae Oulimnius sp. and Elmis sp. (which Schröder et al. (2013) reported as indicator taxa for wood), Riolus sp., the adults of Limnius sp. and the gastropod Ancylus fluviatilis. These feed on the biofilm developing on the LW surface (Hoffmann \& Hering, 2000). As the LW is exposed to swift flow, it may also trap seston in its crevices (Benke \& Wallace, 2003), providing food for some other indicator species such as (partial) collector feeding types: Baetis sp. (Ephemeroptera, Baetidae), Psychodidae (Diptera) and Orthocladiinae (Diptera). Thus, our results from a lowland sand-bed stream are consistent with earlier findings in terms of invertebrate assemblages and diversity.

Overall additive effects of large wood on the river ecosystem

The actual LW habitat only contributes a small proportion to the overall increase in invertebrate diversity in the study reach. Importantly, the diversity of invertebrates in the river sediments around the LW equalled or exceeded that on the LW itself, which is recognized as a hotspot of invertebrate diversity (Hoffmann \& Hering, 2000; Benke \& Wallace, 2003). Thus, we conclude that the widely reported benefits of $L W$ in promoting a more diverse invertebrate community also applies to its surroundings, as far as surveyed in this study $(60 \mathrm{~cm}$ upstream, $160 \mathrm{~cm}$ downstream).

The higher diversity of benthic macroinvertebrate assemblages within the habitats near the LW pieces, and the distinct differences among the assemblages encountered there, were associated with the diversification of habitat properties, including the higher organic matter content of the riverbed sediments. Such heterogeneous environments enable a large number of niches for invertebrates, and easier use of neighbouring habitats during different life cycle stages compared to more homogeneous environments, that are thus dominated by fewer taxa (Beisel, Usseglio-Polatera \& Moreteau, 2000). LW itself may act as a source of colonization for 
nearby mesohabitats, as many invertebrates (e.g. many Trichoptera), use LW for oviposition and LW may trap drifting egg masses (e.g. Lepidostoma basale) (Spänhoff, Alecke \& Meyer, 1999).

We have demonstrated that the presence of LW was associated with the formation of three additional mesohabitats with distinct hydromorphology and macroinvertebrate assemblages: i) the LW piece itself; ii) scouring pools with coarser sediment and greater water depths, flow velocities and turbulence (gravel patch); and iii) sheltered areas rich in organic matter. The various mesohabitat types typical for lowland rivers respond differently to disturbances, such as flood events (Palmer et al., 1996), and thus partially provide refugia for invertebrates (Townsend \& Hildrew, 1994). Our results show that LW is associated with local increases in mean flow velocity, suggesting that LW can provide refugia with high flow velocities during low flow conditions. Overall, the diverse mesohabitats provided by LW are likely to lead to higher resilience of benthic communities, by offering sources for re-colonization after disturbances (Fig. 8).

In conclusion, our study has quantified shifts in several key hydromorphological variables associated with the presence of LW in a lowland sand-bed river. These shifts resulted in the formation of more diverse benthic mesohabitats inhabited by distinct and diverse invertebrate communities. In contrast to findings from LW studies in mountain streams, the presence of LW in the studied lowland river not only enhanced sedimentation but was also associated with scouring processes. Thus, large wood not only forms hotspots of habitat and invertebrate diversity itself, but additionally triggers the formation of similarly diverse habitats in its surroundings. Thus the ecological role of large wood in rivers appears even greater than previously recognized and large wood should remain in river channels wherever possible. Our finding also enables a more precise prediction of attainable restoration effects for rivers impacted by morphological degradation or flow abstraction, as the addition of LW not only 
results in the formation of typical and diverse benthic habitats, but also creates microhabitats that will be exposed to increased flow velocities even at reduced discharge levels (Brunke, Hoffmann \& Pusch, 2001).

\section{Acknowledgments}

This work was carried out within the SMART Joint Doctorate (Science for the MAnagement of Rivers and their Tidal systems) funded with the support of the Erasmus Mundus programme of the European Union. The authors thank Jürgen Schreiber, Marlen Mährlein and Berta Grau Esteve for field and laboratory assistance. The authors also thank two anonymous reviewers whose comments greatly improved an earlier version of the manuscript.

\section{References}

Aqem Consortium. (2008) ASTERICS: AQEM. STAR Ecological river classification system, Version 3.1. www.aqem.de.

Armitage P., Pardo I. \& Brown A. (1995) Temporal constancy of faunal assemblages in 'mesohabitats' - application to management? Archiv Fur Hydrobiologie, 133, 367-387.

Bates D., Maechler M. \& Bolker B. (2012) Ime4: Linear mixed-effects models using S4 classes. http://CRAN.R-project.org/package=Ime4.

Beisel J.-N., Usseglio-Polatera P. \& Moreteau J.-C. (2000) The spatial heterogeneity of a river bottom: a key factor determining macroinvertebrate communities. Hydrobiologia, 422/433, 163-171.

Benke A. \& Wallace J.B. (2003) Influence of wood on invertebrate communities in streams and rivers. In: The ecology and management of wood in world rivers. (Eds S.V. Gregory \& K.L. Boyer \& A.M. Gurnell), pp. 149-177. American Fisheries Society, Symposium 37, Bethesda, Maryland. 
Boon P. (1978) The pre-impoundment distribution of certain Trichoptera larvae in the North Tyne river system (Northern England), with particular reference to current speed. Hydrobiologia, 57, 167-174.

Borcard D., Gillet F. \& Legendre P. (2011) Numerical ecology with R, Springer.

Brunke M., Hoffmann A. \& Pusch M. (2001) Use of mesohabitat-specific relationships between flow velocity and river discharge to assess invertebrate minimum flow requirements. Regulated Rivers: Research \& Management, 17, 667-676.

Buffin-Bélanger T. \& Roy A.G. (2005) 1 min in the life of a river: selecting the optimal record length for the measurement of turbulence in fluvial boundary layers. Geomorphology, 68, 77-94.

Buffington J.M. \& Montgomery D.R. (1999) Effects of hydraulic roughness on surface textures of gravel-bed rivers. Water Resources Research, 35, 3507-3521.

Cáceres M.D. \& Legendre P. (2009) Associations between species and groups of sites: indices and statistical inference. Ecology, 90, 3566-3574.

Corbet P.S. (1980) Biology of odonata. Annual Review of Entomology, 25, 189-217.

Cordova J.M., Rosi-Marshall E.J., Tank J.L. \& Lamberti G.A. (2008) Coarse particulate organic matter transport in low-gradient streams of the Upper Peninsula of Michigan. Journal of the North American Benthological Society, 27, 760-771.

Daniels M.D. (2006) Distribution and dynamics of large woody debris and organic matter in a low-energy meandering stream. Geomorphology, 77, 286-298.

Dobson M. \& Hildrew A.G. (1992) A test of resource limitation among shredding detritivores in low order streams in southern England. Journal of Animal Ecology, 47, 69-77.

Drury D.M. \& Kelso W.E. (2000) Invertebrate colonization of woody debris in coastal plain streams. Hydrobiologia, 434, 63-72.

Dufrêne M. \& Legendre P. (1997) Species assemblages and indicator species: the need for a flexible asymmetrical approach. Ecological Monographs, 67, 345-366. 
Ehrman T.P. \& Lamberti G.A. (1992) Hydraulic and particulate matter retention in a 3rd-order Indiana stream. Journal of the North American Benthological Society, 11, 341-349.

Enders E.C., Boisclair D. \& Roy A.G. (2003) The effect of turbulence on the cost of swimming for juvenile Atlantic salmon (Salmo salar). Canadian Journal of Fisheries and Aquatic Sciences, 60, 1149-1160.

Everett R.A. \& Ruiz G.M. (1993) Coarse woody debris as a refuge from predation in aquatic communities. Oecologia, 93, 475-486.

Gerhard M. \& Reich M. (2000) Restoration of streams with large wood: Effects of accumulated and built-in wood on channel morphology, habitat diversity and aquatic fauna. International Review of Hydrobiology, 85, 123-137.

Gippel C.J., O’Neill I.C., Finlayson B.L. \& Schnatz I. (1996) Hydraulic guidelines for the reintroduction and management of large woody debris in lowland rivers. Regulated RiversResearch \& Management, 12, 223-236.

Gotelli N.J. \& Colwell R.K. (2001) Quantifying biodiversity: procedures and pitfalls in the measurement and comparison of species richness. Ecology Letters, 4, 379-391.

Gurnell A.M. \& Linstead C. (1998) Interactions between large woody debris accumulations, hydrological processes and channel morphology in British headwater rivers. In: Hydrology in a Changing Environment. (Eds Wheater H. \& K. C.), pp. 381 -395. Wiley, Chichester.

Gurnell A.M., Piegay H., Swanson F.J. \& Gregory S.V. (2002) Large wood and fluvial processes. Freshwater Biology, 47, 601-619.

Hamill S., Qadri S. \& Mackie G. (1979) Production and turnover ratio of Pisidium casertanum (Pelecypoda: Sphaeriidae) in the Ottawa River near Ottawa-Hull, Canada.

Hydrobiologia, 62, 225-230. 
Harper D. \& Everard M. (1998) Why should the habitat level approach underpin holistic river survey and management? Aquatic Conservation: Marine and Freshwater Ecosystems, 8, $395-413$.

Hilderbrand R.H., Lemly A.D., Dolloff C.A. \& Harpster K.L. (1997) Effects of large woody debris placement on stream channels and benthic macroinvertebrates. Canadian Journal of Fisheries and Aquatic Sciences, 54, 931-939.

Hoffmann A. \& Hering D. (2000) Wood-Associated Macroinvertebrate Fauna in Central European Streams. International Review of Hydrobiology, 85, 25-48.

Hurlbert S.H. (1971) The nonconcept of species diversity: a critique and alternative parameters. Ecology, 52, 577-586.

Jowett I. (2003) Hydraulic constraints on habitat suitability for benthic invertebrates in gravel-bed rivers. River Research and Applications, 19, 495-507.

Kail J. (2003) Influence of large woody debris on the morphology of six central European streams. Geomorphology, 51, 207-223.

Kail J., Hering D., Muhar S., Gerhard M. \& Preis S. (2007) The use of large wood in stream restoration: experiences from 50 projects in Germany and Austria. Journal of Applied Ecology, 44, 1145-1155.

Keller E.A. \& Swanson F.J. (1979) Effects of large organic material on channel form and fluvial processes. Earth surface processes, 4, 361-380.

Legendre P. \& Gallagher E.D. (2001) Ecologically meaningful transformations for ordination of species data. Oecologia, 129, 271-280.

Lester R.E. \& Boulton A.J. (2008) Rehabilitating agricultural streams in Australia with wood: a review. Environmental management, 42, 310-326.

Liébault F. \& Piégay H. (2001) Assessment of channel changes due to long-term bedload supply decrease, Roubion River, France. Geomorphology, 36, 167-186. 
Mendiburu F.D. (2012) agricolae: Statistical procedures for agricultural research. R package version 1.0-9. http://cran.r-project.org/web/packages/agricolae/index.html.

Montgomery D.R., Collins B.D., Buffington J.M. \& Abbe T.B. (2003) Geomorphic effects of wood in rivers. American Fisheries Society Symposium, 1-27.

Mutz M. (2000) Influences of woody debris on flow patterns and channel morphology in a low energy, sand-bed stream reach. International Review of Hydrobiology, 85, 107-121.

Nakano D., Nagayama S., Kawaguchi Y. \& Nakamura F. (2008) River restoration for macroinvertebrate communities in lowland rivers: insights from restorations of the Shibetsu River, north Japan. Landscape and Ecological Engineering, 4, 63-68.

Noguchi K., Hui W.W., Gel Y., Gastwirth J. \& Miao W. (2009) lawstat: An R package for biostatistics, public policy, and law. R package version 2.4. http://CRAN.Rproject.org/package=lawstat.

O'connor N. (1991) The effects of habitat complexity on the macroinvertebrates colonising wood substrates in a lowland stream. Oecologia, 85, 504-512.

Oksanen J., Blanchet F.G., Kindt R., Legendre P., Minchin P.R., O'hara R.B., Simpson G.L., Solymos P., Stevens M. \& Wagner H. (2013) vegan: Community Ecology Package. R package version 2.0-7. http://CRAN.R-project.org/package=vegan.

Palmer M.A., Arensburger P., Martin A.P. \& Denman D.W. (1996) Disturbance and patchspecific responses: the interactive effects of woody debris and floods on lotic invertebrates. Oecologia, 105, 247-257.

Pardo I. \& Armitage P.D. (1997) Species assemblages as descriptors of mesohabitats. Hydrobiologia, 344, 111-128.

Pritchard G. (1965) Prey capture by dragonfly larvae (Odonata; Anisoptera). Canadian Journal of Zoology, 43, 271-289.

R Core Team. (2013) R: A language and environment for statistical computing $R$ Foundation for Statistical Computing, Vienna, Austria. http://www.R-project.org/. 
Roni P., Beechie T.J., Bilby R.E., Leonetti F.E., Pollock M.M. \& Pess G.R. (2002) A review of stream restoration techniques and a hierarchical strategy for prioritizing restoration in Pacific Northwest watersheds. North American Journal of Fisheries Management, 22, 120.

Schröder M., Kiesel J., Schattmann A., Jähnig S.C., Lorenz A.W., Kramm S., Keizer-Vlek H., Rolauffs P., Graf W. \& Leitner P. (2013) Substratum associations of benthic invertebrates in lowland and mountain streams. Ecological Indicators, 30, 178-189.

Smock L.A., Metzler G.M. \& Gladden J.E. (1989) Role of debris dams in the structure and functioning of low-gradient headwater streams. Ecology, 70, 764-775.

Spänhoff B., Alecke C. \& Meyer E. The colonization of aquatic woody debris by Trichoptera, with special reference to the genus Lype (Psychomyiidae). In: Proceedings of the 9th International Symposium on Trichoptera, pp. 349-3581999.

Townsend C.R. \& Hildrew A.G. (1994) Species traits in relation to a habitat templet for river systems. Freshwater Biology, 31, 265-275.

Wallace J.B., Webster J.R. \& Meyer J.L. (1995) Influence of log additions on physical and biotic characteristics of a mountain stream. Canadian Journal of Fisheries and Aquatic Sciences, 52, 2120-2137.

Webb A.A. \& Erskine W.D. (2005) Natural variability in the distribution, loading and induced scour of large wood in sand-bed forest streams. River Research and Applications, 21, 169-185.

Wohl E. (2013) Floodplains and wood. Earth-Science Reviews, 123, 194-212.

\section{Supporting Information}

Additional Supporting Information may be found in the online version of this article:

Table S1 Complete list of taxa. 
Table 1 Percentages of the water column occupied by the large wood (LW) for each studied substratum type.

Water column occupied by LW (\%)

\begin{tabular}{lccc} 
Replicate & Gravel & Sand & Organic matter \\
\hline LW1 & 36 & 46 & 38 \\
LW2 & 18 & 34 & 68 \\
LW3 & 27 & 42 & 38 \\
LW4 & 23 & 30 & 71 \\
Mean & 26 & 38 & 54 \\
\hline
\end{tabular}


Table 2 Linear mixed effects (LME) analysis of selected environmental variables and invertebrate metrics in order to test the effect of substratum type. The statistics of the likelihood ratio test are reported, as well the model estimations for the substrata organic matter and sand in contrast to gravel. Only those variables and metrics are reported for which the test was significant $(p<0.05)$.

\section{Likelihood ratio tests}

Model estimation ( \pm S.E.)

Organic

\begin{tabular}{lcccccc} 
& transf. & $\mathbf{X}^{2}$ & $\mathbf{d f}$ & $\mathbf{p}$ & matter & Sand \\
\hline Environmental variables & & & & & & \\
Flow velocity $\left(\mathrm{ms}^{-1}\right.$ ) & & 21.57 & 11 & $<0.001$ & $-0.15 \pm 0.02$ & $-0.20 \pm 0.02$ \\
Sorting index & $\log (\mathrm{x}+1)$ & 14.87 & 11 & $<0.001$ & $-1.00 \pm 0.13$ & $-0.99 \pm 0.13$ \\
Depth (cm) & & 20.52 & 11 & $<0.001$ & $-52.45 \pm 6.68$ & $-33.95 \pm 6.68$ \\
Metrics & & & & & & \\
Taxa richness (taxa per sample) & & & & & & \\
Abundance (ind. per sample) & $\log (\mathrm{x}+1)$ & 14.76 & 11 & $<0.001$ & $+1.15 \pm 0.025$ & $-0.33 \pm 0.28$ \\
Active filter feeders (\%) & $\log (\mathrm{x}+1)$ & 10.63 & 11 & 0.004 & $+1.02 \pm 0.25$ & $+0.99 \pm 0.27$ \\
Collectors (\%) & $\log (\mathrm{x}+1)$ & 8.94 & 11 & 0.011 & $-0.54 \pm 0.18$ & $-0.50 \pm 0.19$ \\
Shredders (\%) & $\log (\mathrm{x}+1)$ & 12.02 & 11 & 0.002 & $+0.88 \pm 0.24$ & $+0.62 \pm 0.25$ \\
Grazers (\%) & $\log (\mathrm{x}+1)$ & 10.04 & 11 & 0.006 & $-0.74 \pm 0.25$ & $-0.66 \pm 0.26$ \\
Active filterers (ind. per sample) & $\log (\mathrm{x}+1)$ & 16.24 & 11 & $<0.001$ & $+2.04 \pm 0.28$ & $+0.71 \pm 0.28$ \\
Collectors (ind. per sample) & $\log (\mathrm{x}+1)$ & 8.07 & 11 & 0.018 & $+0.55 \pm 0.18$ & $-0.81 \pm 0.19$ \\
Shredders (ind. per sample) & $\log (\mathrm{x}+1)$ & 19.10 & 11 & $<0.001$ & $+1.64 \pm 0.22$ & $+0.37 \pm 0.28$ \\
Predators (ind. per sample) & $\log (\mathrm{x}+1)$ & 13.73 & 11 & 0.001 & $+1.24 \pm 0.29$ & $-0.42 \pm 0.35$ \\
Grazers (ind. per sample) & $\log (\mathrm{x}+1)$ & 6.43 & 11 & 0.040 & $+0.20 \pm 0.25$ & $-0.74 \pm 0.26$
\end{tabular}


Table 3 Hydraulics and channel morphology at the sampling sites (mean \pm S.E.), as $\mathrm{C}=$ control samples, $\mathrm{LW}=$ large wood surface, $\mathrm{GR}=$ gravel, $\mathrm{SA}=$ sand, $\mathrm{OM}=$ organic matter.

\begin{tabular}{lccccc}
\hline & C (n=4) & LW (n=12) & GR (n=20) & SA (n=20) & OM (n=20) \\
\hline Mean flow velocity $\left(\mathrm{ms}^{-1}\right)$ & $0.333 \pm 0.005$ & $0.420 \pm 0.014$ & $0.344 \pm 0.030$ & $0.144 \pm 0.008$ & $0.190 \pm 0.023$ \\
Turbulence $\left(\mathrm{ms}^{-1}\right)$ & $0.057 \pm 0.007$ & $0.055 \pm 0.004$ & $0.091 \pm 0.007$ & $0.064 \pm 0.004$ & $0.048 \pm 0.004$ \\
Depth $(\mathrm{cm})$ & $59.50 \pm 3.30$ & $36.25 \pm 0.57$ & $105.25 \pm 5.96$ & $71.30 \pm 4.89$ & $52.80 \pm 6.63$ \\
Median sediment grain size (mm) & $0.51 \pm 0.02$ & - & $1.75 \pm 0.49$ & $0.30 \pm 0.02$ & $0.24 \pm 0.02$ \\
Sediment sorting index & $0.29 \pm 0.04$ & - & $3.26 \pm 0.67$ & $0.24 \pm 0.08$ & $0.24 \pm 0.09$ \\
Sediment organic matter (\%) & $0.77 \pm 0.38$ & - & $2.26 \pm 0.47$ & $1.60 \pm 0.47$ & $5.08 \pm 1.36$ \\
\hline
\end{tabular}


Table 4 Indicator taxa per each substratum type are listed together with their significance level $\left({ }^{* *} \mathrm{p}<0.01,{ }^{*} \mathrm{p}<0.05\right) . \mathrm{L} .=$ larvae, $\mathrm{A} .=$ adults. No indicator taxa were found for sand and control samples.

\begin{tabular}{|c|c|c|}
\hline Large wood & Organic matter & Gravel \\
\hline Hemerodromia sp. ${ }^{* *}$ & Gammarus roeselii ** & Limnius sp. L. ${ }^{\star \star}$ \\
\hline Macronichus quadrituberculatus $L .{ }^{* *}$ & Pisidium sp. ${ }^{* *}$ & Hydropsyche pellucidula * \\
\hline Elmis sp. L. ${ }^{* *}$ & Gammaridae ** & \\
\hline Hydropsyche siltalai ** & Micronecta sp. ${ }^{* *}$ & \\
\hline Baetis sp. ** & Atrichops crassipes ** & \\
\hline Orthocladiinae ** & Chironominae ** & \\
\hline Lype sp. ${ }^{* *}$ & Hydracarina ** & \\
\hline Ancylus fluviatilis ** & Ceratopogoninae ** & \\
\hline Hydroptilidae ** & Gomphus sp. ** & \\
\hline Oulimnius sp. $L .{ }^{* *}$ & Sphaerium sp. ** & \\
\hline Psychodidae ** & Potamopyrgus antipodarum ** & \\
\hline Riolus sp. L. * & Limnephilidae ** & \\
\hline Limnius sp. A. * & $\begin{array}{l}\text { Paraleptophlebia submarginata ** } \\
\text { Calopteryx sp. }{ }^{*} \\
\text { Ophiogomphus cecilia* * }\end{array}$ & \\
\hline
\end{tabular}




\section{Figure legends}

Figure 1 Location of the study area

Figure 2 PCA for environmental variables. Arrows define the gradients of the environmental variables. Ellipses show the $95 \%$ confidence interval per each substratum type, as $\mathrm{C}=$ control samples, GR=gravel, $\mathrm{SA}=$ sand, $\mathrm{OM}=$ organic matter.

Figure 3 Radar graphs of the abiotic variables recorded in A) the area surrounding the LW (LW, gravel, sand and organic matter, and B) in the control sites. The values are reported as percentages, with the maximum recorded values (in both LW and control sites) per each variable set as $100 \%$. Grey areas represent the ranges of the variables, dotted lines represent the mean values. $\mathrm{OM}=$ organic matter.

Figure 4 Diversity metrics for the invertebrate communities on the various substratum types (mean \pm S.E. $): C=$ control samples, $\mathrm{LW}=$ large wood surface, $\mathrm{GR}=$ gravel, $\mathrm{SA}=\mathrm{sand}, \mathrm{OM}=$ organic matter. Kruskal-Wallis test significances: Abundance $p<0.001$; Taxa richness $p<0.001$; Evenness $p=0.006$; Shannon-Wiener diversity index $p=0.005$. Letters indicate the results of Kruskal-Wallis pairwise post-hoc comparisons with Bonferroni correction (different letters indicate significant difference, $\mathrm{p}<0.05)$.

Figure 5 Relative abundances of the feeding groups in the various substratum types (mean \pm S.E. ): $\mathrm{C}=$ control samples, $\mathrm{LW}=$ large wood surface, $\mathrm{GR}=$ gravel, $\mathrm{SA}=$ sand, $\mathrm{OM}=$ organic matter. Only the metrics for which Kruskal-Wallis test was significant $(p<0.05)$ are reported: \% Grazers $p<0.001 ; \%$ Collectors $p=0.001 ; \%$ Shredders $p<0.001 ; \%$ Xylophagous $p=0.027$. Letters indicate the results of Kruskal-Wallis pairwise post-hoc comparisons with Bonferroni correction (different letters indicate significant difference, $p<0.05$ ). 
Figure 6 Non-metric multidimensional scaling of invertebrate samples. Ellipses show the 95\% confidence interval per each group, as $\mathrm{C}=$ control samples, $\mathrm{LW}=$ large wood surface, $\mathrm{GR}=$ gravel, $\mathrm{SA}=$ sand, $\mathrm{OM}=$ organic matter.

Figure 7 RDA ordination of invertebrate communities and governing environmental variables conditioned on large wood (LW), in order to remove the variation caused by individual LW logs. Arrows define the gradients of the environmental variables. Ellipses show the $95 \%$ confidence interval for each substratum type, $\mathrm{GR}=$ gravel, $\mathrm{SA}=$ sand, $\mathrm{OM}=$ organic matter. Samples from the LW surface and control samples were excluded because we were interested in the abiotic factors producing biotic diversity around the LW and because of their interaction with the effects of substratum and distance (i.e. LW samples were the only ones at distance $=0 \mathrm{~cm}$, control samples at distance $>10 \mathrm{~m}$ ). Crosses show taxa. Abbreviations of taxa plotted outside of the centre of the graph: Pis= Pisidium sp.; Gam= Gammaridae; Gam.roe= Gammarus roeselii; Lep.bas= Lepidostoma (Lasiocephala) basale; $\mathrm{Sim}=$ Simuliidae; Bae= Baetis sp.; Sph= Spaerium sp.; Aph.aes $=$ Aphelocheirus aestivalis; Oli= Oligochaeta .

Figure 8 Conceptual representation of the cascading ecological effects of a piece of large wood (LW, as a tree trunk) introduced into a lowland river. The presence of the LW will trigger formation of more diverse mesohabitats in its vicinity, and the highly diverse and abundant assemblages on the LW surface will act as hotspots from which macroinvertebrates can colonize nearby habitats. These will lead to more diverse invertebrate assemblages and a more resilient ecosystem. 
Figure 1

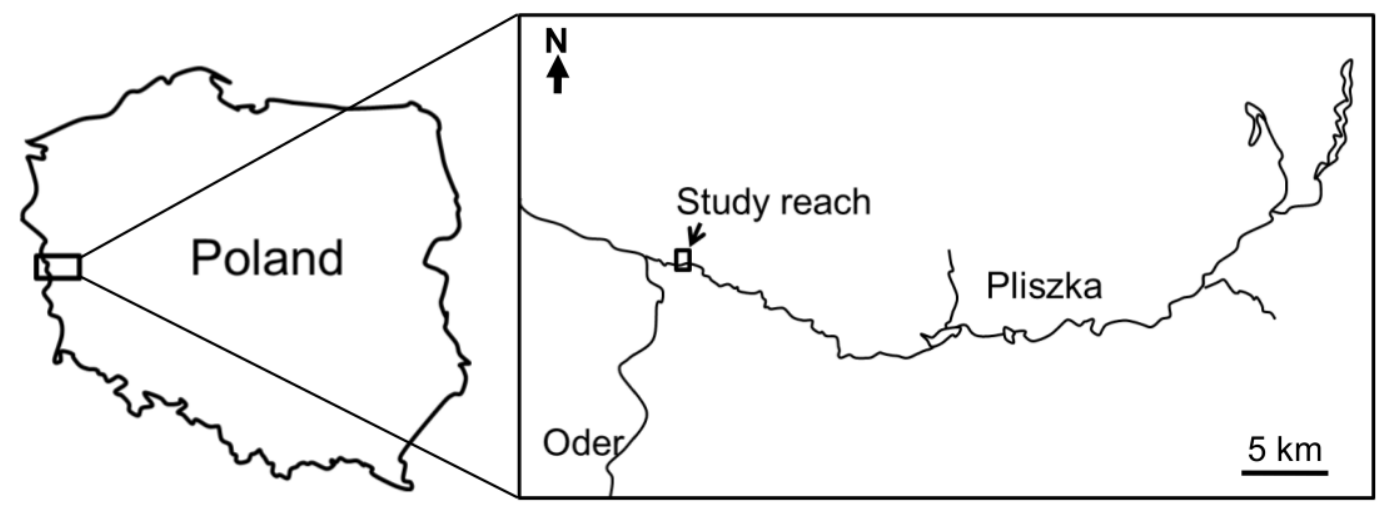


Figure 2

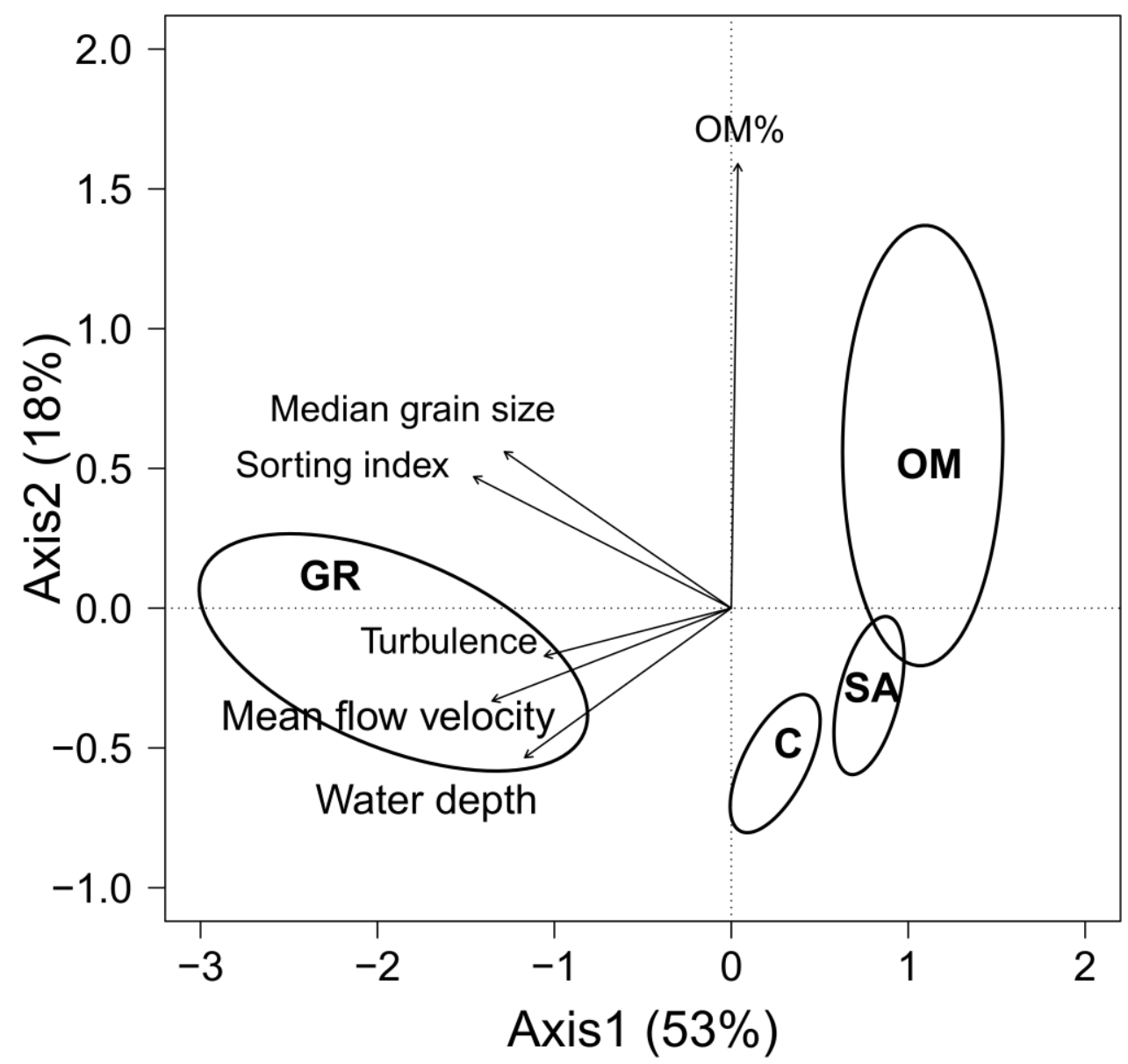


Figure 3

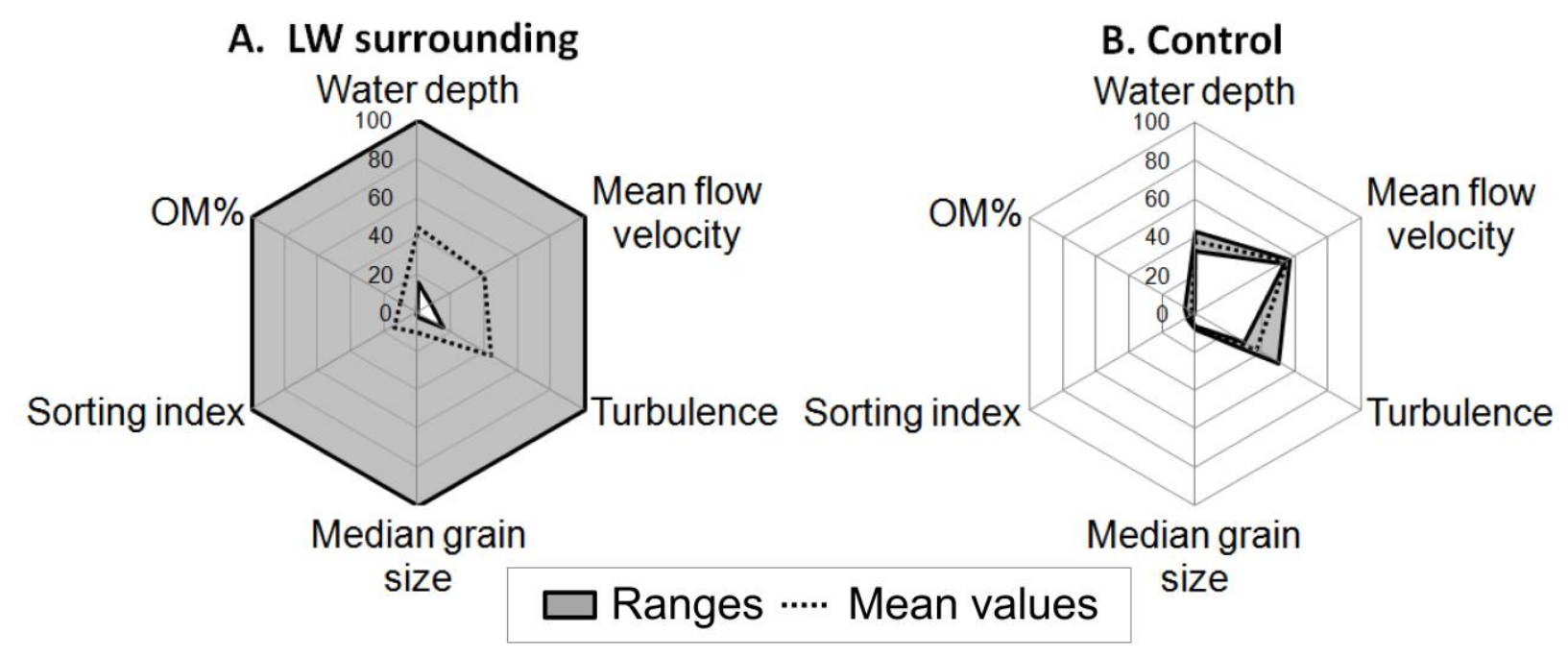


Figure 4
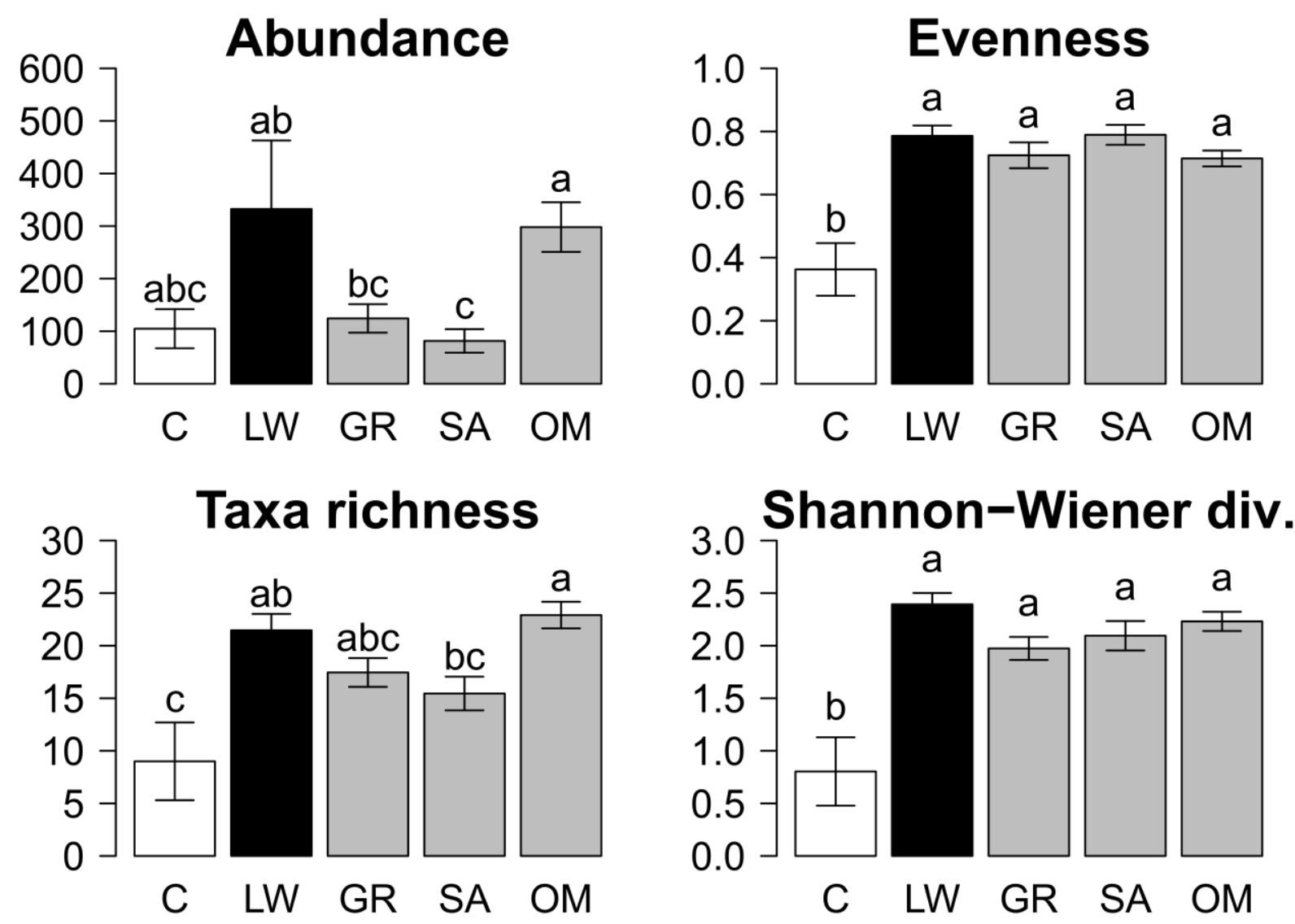
Figure 5
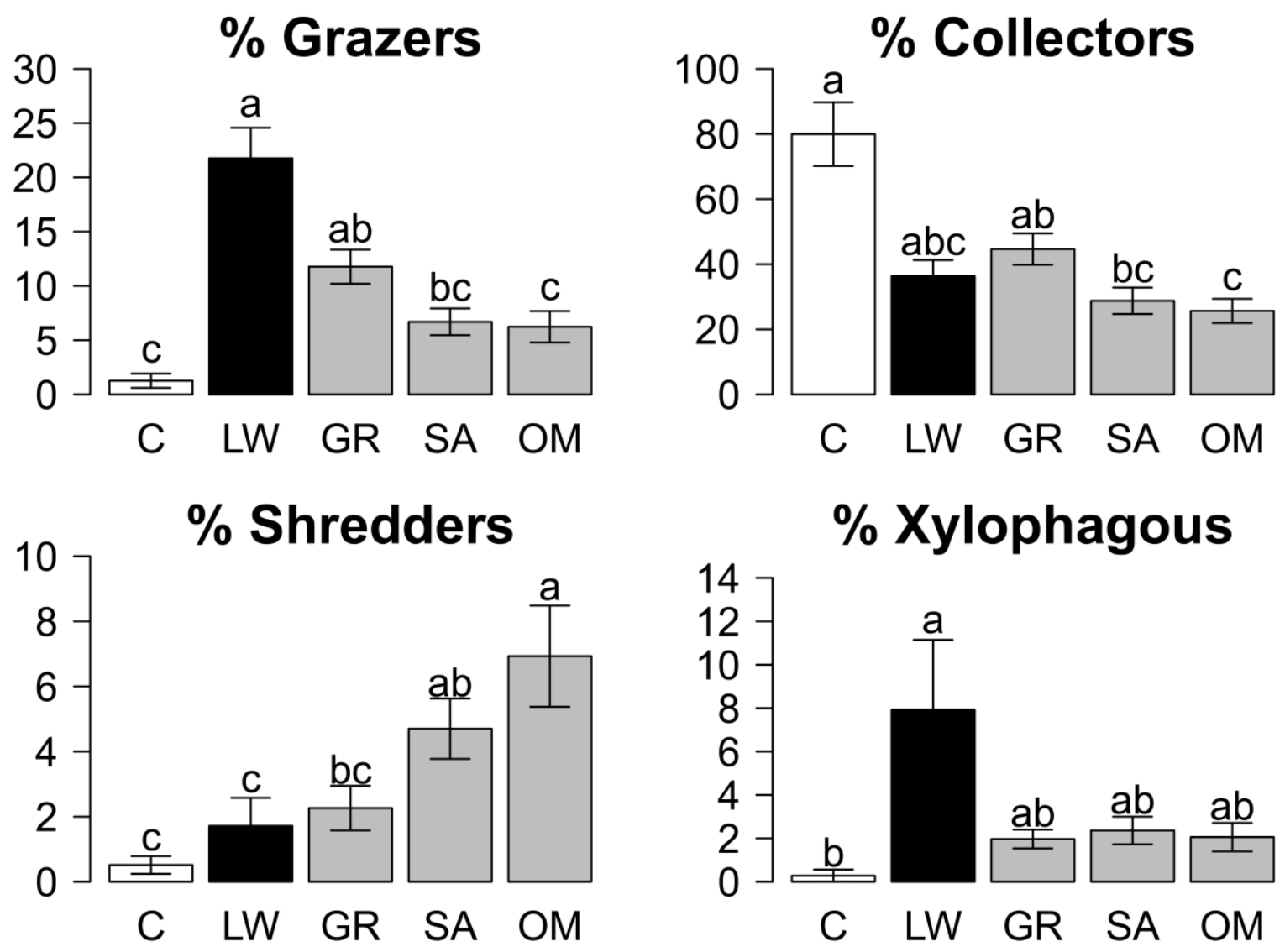
Figure 6

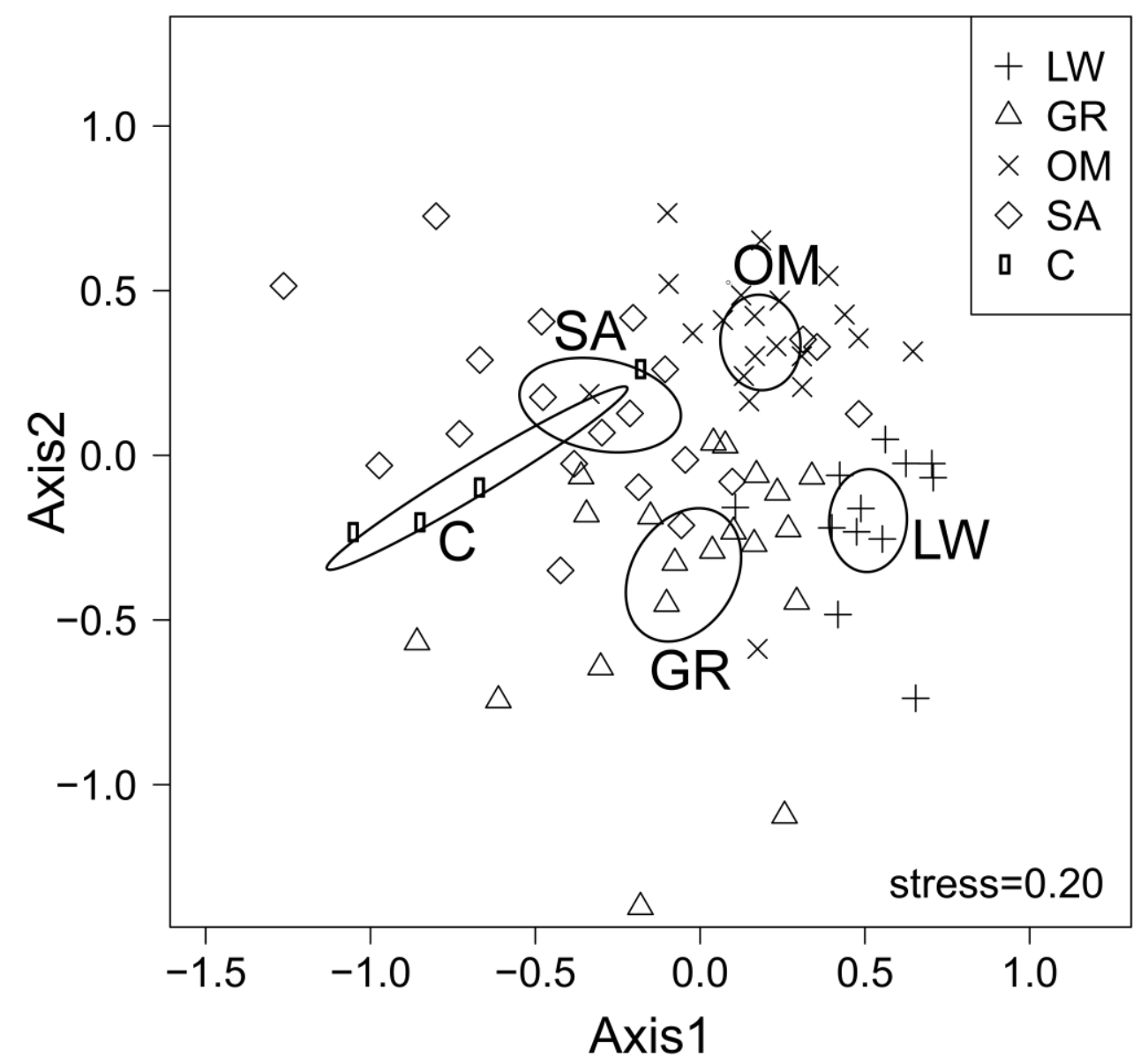


Figure 7

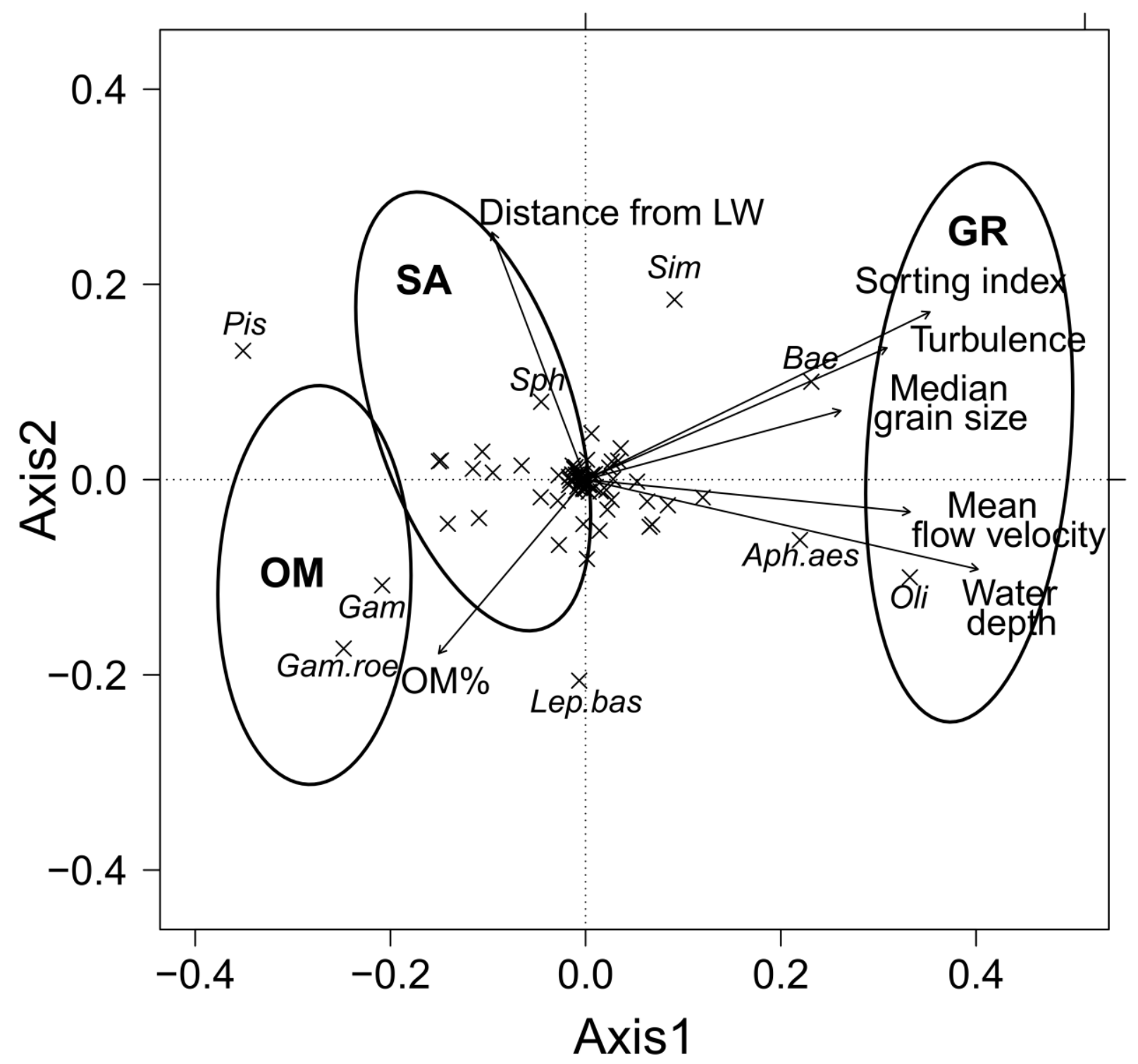


Figure 8

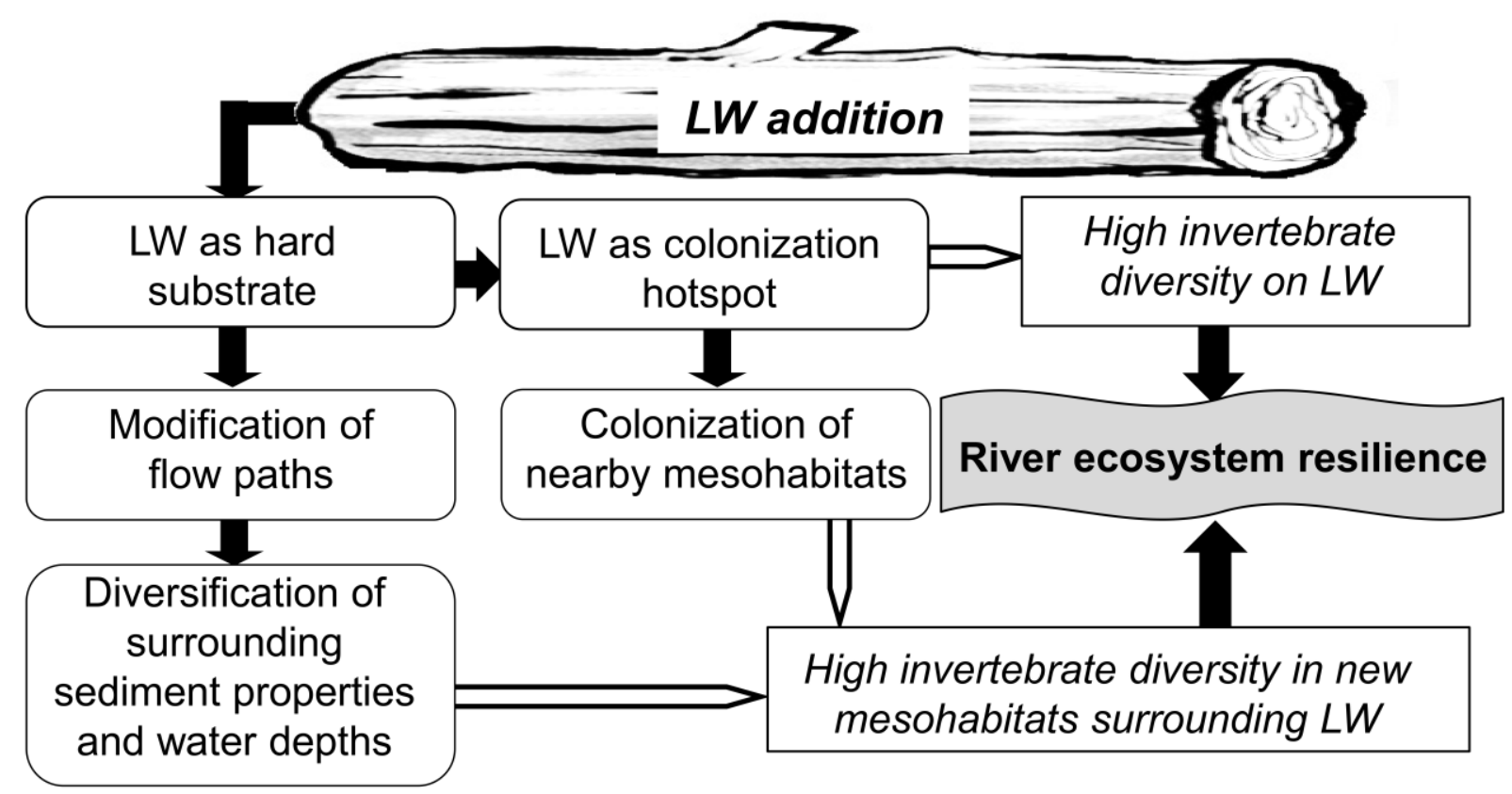

